\title{
Amizade na adolescência e a entrada na universidade ${ }^{1}$
}

\section{Friendship in adolescence and college admission}

\section{Suellen I brahim Peron}

Graduanda em Psicologia da Universidade Federal de Minas Gerais - UFMG, Belo Horizonte, MG, Brasil

\section{Luisa Schivek Guimarães}

Graduanda em Psicologia da Universidade Federal de Minas Gerais - UFMG, Belo Horizonte, MG, Brasil

\section{Luciana Karine de Souza*}

Docente da Universidade Federal de Minas Gerais - UFMG, Belo Horizonte, MG, Brasil

\begin{abstract}
RESUMO
O presente estudo investigou o relacionamento de amizade em jovens que recém-ingressaram na universidade. Os aspectos estudados da amizade foram: freqüência de amizades, presença de melhor amizade, origem, duração, influências de outros contextos de interação (família, romance, escola), freqüência de contato e presença de melhores amizades extras. Integraram a amostra 24 estudantes com idade entre 16 e 17 anos, regularmente matriculados em cursos de graduação na Universidade Federal do Rio Grande do Sul, em Porto Alegre, envolvendo diversas áreas do conhecimento. O estudo procura contribuir para uma melhor compreensão desta fase peculiar da vida de alguns adolescentes - o ingresso na universidade. Além disso, abre possibilidades para futuras investigações que promovam um melhor entendimento sobre este tema de pesquisa e de intervenção.
\end{abstract}

Palavras-chave: Amizade, Adolescente, Universidade, Desenvolvimento.

\begin{abstract}
This study investigated friendship in youngsters that had just been admitted into college. The friendship aspects under study were: frequency of friends, presence of a best friend, origin, duration, influence from other contexts of interaction (family, romance, school), frequency of contact and presence of extra-best friends. The sample was composed of 24 adolescents, from 16 to 17 years-old, registered in major courses at Universidade Federal do Rio Grande do Sul, in Porto Alegre, south of Brazil, comprising diverse areas of knowledge. The study aims at contributing to a better understanding of this peculiar life-phase for some adolescents - admission into college. In addition to that, this study brings about possibilities concerning future investigations that evince a better understanding about this research and intervention topic.
\end{abstract}

Keywords: Friendship, Adolescent, College, Development. 
De acordo com a Organização Mundial de Saúde (OMS), a adolescência diz respeito ao período compreendido entre 10 e 19 anos de idade (MARTINS; TRINDADE; ALMEIDA, 2003). No Brasil, o Estatuto da Criança e do Adolescente (ECA) (1990), no entanto, estabelece o período da adolescência entre 12 e 18 anos. Na literatura científica internacional é possível notar a menção à adolescência até os 21 anos de idade, correspondendo aproximadamente ao final do período universitário conhecido como college nos Estados Unidos. A despeito dos marcadores cronológicos escolhidos para delimitar o início e o final da adolescência, esta fase é a mais recente incluída nos estudos em desenvolvimento humano, ainda apresentando discrepâncias em torno de suas características principais. Desse modo, a adolescência é uma etapa da vida que merece atenção e investigação redobradas por parte de profissionais da saúde, dentre eles o psicólogo.

Segundo Martins, Trindade, Almeida (2003), a adolescência refere-se à fase na qual ocorrem diversas mudanças de âmbito biológico, social e cognitivo. Stanley Hall é apontado como um dos primeiros estudiosos desse período, sendo considerado "o pai da Psicologia da Adolescência". Para S. Hall trata-se de uma época tempestuosa da vida, oriunda de tendências contraditórias: energia, exaltação, superatividade, de um lado; indiferença, letargia e desprezo, de outro (MARTIN; TRINDADE; ALMEIDA, 2003).

Na análise de Ozella (2002), a adolescência passa a ser considerada um período especial no processo de desenvolvimento humano com a idéia de Erik Erikson sobre a confusão de papéis e dificuldade de estabelecer identidade, característicos desta fase. Para Erikson (1976), os progressos tecnológicos ocasionaram um aumento entre o começo da vida escolar e o acesso ao trabalho especializado, o que fez com que a adolescência fosse concebida como um período acentuado e consciente. Assim, essa fase alcançou um estilo de vida típico entre a infância e a idade adulta.

Ariès (1981), na obra "História Social da Criança e da Família", aborda a demarcação científica fornecida às fases da vida, afirmando que, na verdade, trata-se de marcadores artificiais para naturalizar as "idades da vida". Segundo o autor, a adolescência - cuja noção surge no séc. XVIII e como termo apenas no XX - é um período histórica e socialmente construído, com características ímpares a depender da cultura na qual o sujeito se insere. Na letra de uma canção do séc. $X X$, Ariès observa que o adolescente é descrito como um indivíduo dotado de "pureza (provisória), força física, de naturismo, de espontaneidade e de alegria de viver que faria do adolescente o herói do nosso século XX, o século da adolescência" (p. 46).

Anna Freud também atribuiu importância à adolescência, considerando-a como um estágio do desenvolvimento humano de relevância para a formação do caráter do indivíduo. Assim como para 
S. Hall e para Erikson (1968/1976), a autora concebe o período em questão como caracterizado por turbulências (MARTINS; TRINDADE; ALMEIDA, 2003). No entanto, Ozella (2002) questiona a concepção de que a adolescência é um período marcado por conflitos. Para este autor não se trata de uma fase natural e universal do desenvolvimento humano, mas de um momento de vida significado, interpretado e criado historicamente pelos homens. Tal significação e interpretação ocorrem a partir de marcadores biológicos e fisiológicos que a sociedade destaca e que não são focalizados em outros momentos da vida, mesmo quando presentes. Essa representação da adolescência depende diretamente da cultura e das classes sociais nas quais os indivíduos se inserem. Apesar da divergência teórica entre Erikson (1976) e Ozella (2002), ambos defendem que a adolescência tem origem no adiamento do ingresso no mercado de trabalho e na conseqüente extensão do período escolar, geradas por uma sociedade de funcionamento capitalista. Portanto, é possível concluir que algumas idéias propostas de Erikson refletem ainda tendências atuais em desenvolvimento humano.

Outro autor que apresentou uma perspectiva crítica em relação à concepção tradicional de adolescência foi Bandura (apud GÜNTHER, 1996). Para Bandura muitas das suposições negativas sobre esse período se originam do sensacionalismo da mídia e de generalizações inapropriadas feitas a partir de amostras clínicas de comportamentos incomuns. Assim, estes comportamentos devem ser vistos como resultantes de experiências ambientais, e não como características típicas de uma fase conturbada.

Há atualmente uma nova tendência no meio acadêmico em perceber a adolescência não mais como um período de turbulência para o jovem, mas sim para seus pais. Muito da representação deste período da vida como uma fase marcada por crises teve origem em uma visão adultocêntrica, ou seja, uma visão do jovem a partir dos valores e expectativas dos adultos (OZELLA, 2002). Rayou (2005) ressalta a importância de adotar uma posição menos adultocêntrica ao estudar assuntos referentes à experiência de crianças e jovens, principalmente ao entrevistá-los, pois há o risco de direcionar as respostas dos entrevistados. Na pesquisa de Rayou (2005), através da qual se permitiu que os adolescentes falassem à vontade na entrevista, o tema da amizade ocupou quase a totalidade do conteúdo expresso.

Martins, Trindade, Almeida (2003) compararam as representações sociais de adolescentes de zona urbana e rural sobre esta fase da vida. Nos resultados, notou-se que a discrepância encontrada entre as amostras sobre a concepção de adolescência ocorreu em virtude do caráter historicamente construído deste período da vida.

De acordo com Marques (1993), as relações românticas, de amizade e de família são as mais representativas das várias dimensões que 
pode assumir o conceito de intimidade. No entanto, ainda não há um consenso em relação ao que caracteriza uma relação íntima. Para Erikson (apud MONSOUR, 1992), por exemplo, o contato sexual é uma manifestação central da intimidade nas relações com as pessoas do sexo oposto, enquanto para Sullivan (apud MONSOUR, 1992) o contato sexual é uma questão separada da intimidade.

Cordeiro (2006) considera a intimidade como uma "relação emocional caracterizada pela concessão mútua de bem-estar, pelo consentimento implícito para revelação de assuntos privados, podendo envolver a esfera dos sentidos (toque, proximidade do corpo, etc.) e pela partilha de interesse em atividades comuns". Para esse autor, é na adolescência que as verdadeiras relações de amizade baseadas na intimidade emergem, na medida em que nessa fase há uma maior capacidade em expressar valores, como, por exemplo, a honestidade. Estudiosos salientam a diferença de sexo na vivência de relações desse nível, afirmando que, na metade da adolescência, as meninas demonstram mais aptidões para o estabelecimento dessas relações íntimas (JONES; DEMBO apud CORDEIRO, 2006; SULLIVAN, 1953). Alguns estudos estruturam o conceito de intimidade/amizade íntima na adolescência em oito dimensões. São elas: sinceridade e espontaneidade, sensibilidade e conhecimento, vinculação, exclusividade, dádiva e partilha, imposição, atividades comuns, confiança e lealdade (SHARABANY, 1994). Como argumentado por Pereira e Garcia (2007), as amizades são as principais fontes de intimidade na adolescência.

Minto, Pedro, Netto, Bugliani e Gorayeb (2006) argumentam que o estudo das relações de amizade na adolescência é de grande importância visto que o afastamento da família por parte dos jovens e - estreitamento dos laços com os pares é uma importante característica deste período. As mudanças sociais, políticas, culturais e econômicas ocorridas nos últimos anos do século passado e no início do presente século motivaram novas configurações sociais: os papéis sociais tornaram-se mais permeáveis e propícios a mutações. Tais mudanças trouxeram certa instabilidade geradora de angústia nos adolescentes, por não compreenderem o seu lugar social. Esta pode ser a razão para o aumento da importância dos pares em detrimento da família, na medida em que eles compartilham tal situação e proporcionam apoio emocional (PEREIRA; GARCIA, 2007). De acordo com Erikson (1976), há uma tendência de os jovens ajudarem uns aos outros formando turmas e estereotipando-se a si próprios, seus ideais e seus inimigos, além de testarem insistentemente a capacidade para a lealdade.

Araújo e Gomes (1998) investigaram as expectativas de adolescentes de Porto Alegre (RS) em relação aos efeitos do álcool. Observou-se que os adolescentes pertencentes ao padrão que utiliza álcool com maior freqüência normalmente compartilham esse uso com o grupo 
de amigos, e que beber faz parte da amizade. Além disso, os efeitos da ingestão de bebidas alcoólicas podem atuar como facilitadores da aceitação pelo grupo de amigos, especialmente para os adolescentes incluídos neste padrão. Os resultados mostraram ainda que no padrão em que não há uso de álcool, os entrevistados saem com amigos que também não bebem. Segundo os autores, os adolescentes se influenciam mutuamente, modelando o comportamento de beber, já que o grupo se apresenta como uma fonte de entretenimento, gratificação e validação de status para estes jovens que lutam por aceitação no mundo adulto.

Pereira e Garcia (2007) conduziram uma investigação sobre a influência da amizade na escolha profissional com 96 adolescentes com idades entre 15 e 18 anos, estudantes do 20 ano do ensino médio de uma escola particular de Vitória (ES). Dentre os principais resultados, notou-se uma grande participação dos amigos na escolha da profissão, embora esta influência tenha sido relatada como pouco percebida pelos participantes. Na visão dos autores, é possível supor que essa participação dos amigos esteja relacionada a uma cooperação entre pares na busca de uma profissão. A natureza desse objetivo sofreria, dessa forma, uma influência maior de pessoas que estão situadas em uma posição hierarquicamente superior em relação ao desenvolvimento profissional, como os pais e professores. Assim, a cooperação dos amigos consiste na troca de informações sobre carreiras e cursos, opiniões sobre as opções selecionadas pelos estudantes e apoio social mútuo, principalmente em aspectos emocionais do processo de escolha profissional.

São ainda escassos os estudos brasileiros que investigam especificamente a amizade na adolescência. Pylro (2007), por exemplo, abordou a influência do uso da Internet sobre as amizades de adolescentes de Vitória (ES), observando que a Internet é um "instrumento para aglutinar, reordenar e delimitar grupos de amigos que já se conheciam pessoalmente e passaram a construir um sentimento de maior proximidade" (p. 5). Lema (1997) investigou a amizade na fase final da adolescência em 388 universitários de Porto Alegre (RS) com idade entre 17 e 21 anos. Mais especificamente, a autora estudou a intimidade e a competência em dar apoio, comparando relações de amizade com relações entre pessoas conhecidas. Dentre as principais conclusões, Lema (1997) encontrou que a intimidade exerce forte impacto sobre a habilidade de apoiar os amigos. Também Silva et al. (2004) dedicaram-se sobre amizade em adolescentes, focalizando o número de amigos. Estes autores notaram, em adolescentes de 11 a 18 anos, que as meninas tem entre dois e três amigos íntimos, ao passo que os meninos possuem quatro ou mais amigos deste tipo.

Entende-se amizade como uma interação diádica recíproca e íntima, iniciada por livre escolha e marcada por um forte componente afetivo. 
Tal interação tem, como principais funções, a promoção de afeto, intimidade e segurança. Além disso, a amizade também pode ter influência positiva na aprendizagem de crianças e adolescentes, na medida em que, a partir da geração de sentimentos e experiências que possibilitam certa redução de ansiedade, pode estimular atividades de exploração do ambiente e de novos conteúdos. As relações de amizade têm crucial importância, também, no que diz respeito ao desenvolvimento de habilidades sociais como cooperação e resolução de conflitos (LISBOA; KOLLER, 2003).

$O$ estreitamento dos laços com os pares na adolescência é observado também no início da vida universitária. Segundo Pagotti e Pagotti (2005), no ingresso na universidade os laços familiares se fragilizam e a busca por novidades (inclusive amigos e afetos) é mais acentuada. O jovem adulto (de 18 a 25 anos) vivencia desafios de integração que são importantes para o desenvolvimento da autonomia e da intimidade (MOREIRA, 2007). Nesse sentido, a pesquisa sobre as relações de amizade íntima no contexto da vida dos adolescentes e jovens ingressantes na universidade faz-se necessária. Trata-se de relacionamentos determinantes na construção da identidade do indivíduo e na construção de seus ideais, valores e objetivos para a vida adulta, além do sentimento de pertença e da auto-estima (CORDEIRO, 2006).

$O$ ingresso no ensino superior possui, no Brasil, um significado importante para muitos adolescentes, a ponto de ser considerado, por alguns autores, como um rito de passagem da adolescência para o início da vida adulta (SILVA; SOARES, 2001). A literatura brasileira sobre a entrada na universidade é extensa, e foge ao presente objetivo citá-la. No entanto, dois trabalhos exemplificam o papel das relações de amizade nos adolescentes que ingressam no ensino superior. Igue, Bariani e Milanesi (2008) perceberam, no contato com 203 universitários do Estado de São Paulo, que o âmbito interpessoal da vida do ingressante, especialmente sua integração social, afeta diretamente seu compromisso com a instituição e com os estudos universitários. Portes (2001) analisou cinco estudantes de graduação de origem humilde sobre sua vida acadêmica na Universidade Federal de Minas Gerais. O autor observou preconceito de colegas frente à condição financeira difícil dos cinco estudantes, com melhores condições de fazer amizade com indivíduos de condição financeira semelhante ou de outras minorias sociais. Acima de tudo, os participantes do estudo de Portes (2001) salientaram a importância de se ter pelo menos um amigo que seja confidente sobre os momentos difíceis da trajetória acadêmica.

Para Carbery e Buhrmester (1998), dentre as fases da vida definidas como celibatária (indivíduos solteiros e não comprometidos seriamente com parceiro romântico), marital (casal sem filhos) e parental (casal com filhos pequenos), a amizade tem sua fase de 
maior significância funcional na rede de relacionamentos na primeira delas. Isso ocorre devido ao fato de que, na fase celibatária da adultez jovem os amigos são fontes primárias de apoio social, companheirismo e confidências.

Rawlins (1992) afirma que o ingresso na universidade exige da pessoa uma adaptação emocional para poder construir um novo sistema de apoio social e renegociar os relacionamentos com a família e com as amizades pré-existentes à faculdade. Para o autor, este período de transição para a adultez é chamado de período universitário (dos 17 aos 22 anos de idade). Nesta etapa, os estudantes são formalmente educados para a futura profissão; experimentam, em conjunto, alternativas de carreira e de estilos de vida, no encontro destes com os próprios relacionamentos pessoais e valores; e estão com as faculdades físicas e mentais no pico de suas capacidades. Em outras palavras, vivenciam juntos desafios e dúvidas semelhantes, tanto sociais como intelectuais, e uma grande expectativa quanto ao que a vida adulta trará após a universidade (Levinson apud RAWLINS, 1992). Assim, o período universitário é favorável à formação de amizades intensas e estimulantes, na concepção de Rawlins (1992).

Em uma pesquisa que investigou as preocupações mais freqüentes em jovens universitários de Uberlândia (MG) com idade entre 17 e 22 anos, observou-se a importância dos laços afetivos nessa fase. Mais da metade dos estudantes manifestou temer a perda de um amigo e, além disso, a dor existencial de "não ter amigos" também apareceu como preocupação na amostra (PAGOTTI; PAGOTTI, 2005). Essa preocupação é pertinente na medida em que não ter amigos íntimos é uma fonte significativa de estresse, como também foi apontado por Marques (1993).

Oliveira e Costa (1995) propuseram a adolescentes de Belo Horizonte (MG) a elaboração de um dilema que tinham vivenciado e de um dilema que tinham observado na vida de outra pessoa. Todos os dilemas produzidos foram categorizados, resultando três grupos: dilemas morais (classificados em individuais, interpessoais e sociais), dilemas emocionais e dilemas racionais. Os dilemas morais interpessoais vividos pelos próprios estudantes foram os mais citados (94\%), com maior freqüência no tema familiar (65\%), seguido pelo grupo de pares (29\%), no qual foram incluídos amigos e namorados. Já dentre os dilemas morais interpessoais observados na vida de outras pessoas, os amigos e colegas foram citados em $76 \%$ dos dilemas elaborados. Na visão de Oliveira e Costa (1995), “o amigo apareceu predominantemente como a pessoa que vive problemas capazes de despertar empatia por parte do outro, mais do que como agente desencadeador de conflitos" (p. 88).

A literatura empírica estrangeira é extensa sobre amizade em adolescentes. Tradicionalmente é conhecido que as amizades de 
crianças mais velhas e de adolescentes incluem aspectos mais abstratos, como lealdade, confiança e intimidade, requerendo interesses em comum e comprometimento, tanto para manter os amigos como para que se formem novas amizades, além de competição e conflitos (BUKOWSKI; NEWCOMB; HARTUP, 1989, 1996). Como exemplo de pesquisa mais recente, o trabalho de Poulin e Pedersen (2007), que investigou diferenças de gênero na amizade de adolescentes durante cinco anos (da 6a à 10a série), encontrou que o crescimento identificado na proporção de amizades de sexo oposto foi bem maior nas meninas. Além disso, chamou a atenção o resultado de que, tanto para meninos como para meninas, ao se ter uma amizade com uma menina recebe-se mais ajuda do na amizade com um indivíduo do sexo masculino.

0 presente estudo tem por objetivo investigar o relacionamento de amizade em 24 jovens que recém ingressaram na universidade. Os aspectos investigados da amizade foram os mesmos abordados na pesquisa conduzida anteriormente por Souza e Hutz (2007a, 2007b), a saber: número de amizades, presença de melhor amizade, origem, duração, influências de outros contextos de interação (família, romance, escola), frequência de contato e presença de outras melhores amizades.

\section{Método}

\section{Participantes}

Integraram a amostra deste estudo 24 estudantes regularmente matriculados em cursos de graduação na Universidade Federal do Rio Grande do Sul, em Porto Alegre (RS), envolvendo diversas áreas do conhecimento, sendo $37,5 \%$ estudantes de administração, $21 \%$ de pedagogia, $21 \%$ de letras e $20,5 \%$ de outros cursos. Os participantes têm 16 e 17 anos de idade, com média de 16,91 anos (Desvio Padrão $=0,28)$. Todos cursam o primeiro período da graduação e residem na capital gaúcha. Quanto ao sexo dos indivíduos que compuseram a amostra, 14 são do sexo feminino (58\%) e 10 do sexo masculino (42\%). Em relação ao estado civil, $54 \%$ dos participantes são solteiros e $46 \%$ estão envolvidos em um namoro ou noivado.

Outros dados sociodemográficos coletados com os participantes foram: $92 \%$ mora com familiares e $4 \%$ mora sozinho; $12,5 \%$ residem com 1 pessoa, enquanto $83,5 \%$ com 2 a 4 pessoas; $29 \%$ freqüentam outros cursos (por exemplo, escola de idiomas); $46 \%$ praticam atividades físicas; $33 \%$ são sócios de clubes ou associações; $92 \%$ possuem hobby ou lazer; $79 \%$ são católicos e $33 \%$ do total da amostra praticam sua religião.

\section{I nstrumentos}

No presente estudo foram analisados os dados coletados com os instrumentos Questionário Sócio-demográfico (QSD), Questionário 
Introdutório de Amizade (QIA) e Questionário Complementar de Amizade (QCA). O QSD requer do participante dados como sexo, idade, estado civil, atividade remunerada, número de irmãos, pessoas com quem reside, religião, lazer, etc. O QIA solicita a indicação de até dez amizades mais próximas, situando-as em termos de sexo, cidade de residência e a indicação de uma melhor amizade. O QCA apresenta questões específicas sobre esta melhor amizade do participante, como duração, origem, distância geográfica, frequência de contato, tipo de relacionamento atual com este melhor amigo, conhecimento dele sobre o status de melhor amizade, e indicação de amizades extras. Ao final do QCA, há a seguinte questão aberta: "Existe algum aspecto da amizade que em sua opinião é importante e que não foi mencionado neste questionário? Por que este aspecto é importante?".

\section{Procedimentos}

A coleta de dados foi realizada utilizando-se um conjunto de questionários organizados para uma investigação anterior, conduzida para o estudo de amizades em jovens adultos com idade mínima de 18 anos (SOUZA; HUTZ, 2007a, 2007b). Contudo, 24 estudantes de 16 e 17 anos de idade foram excluídos daquela pesquisa, mas foram analisados na presente oportunidade.

Todos os questionários foram aplicados seqüencialmente e respondidos pelos universitários participantes, em um período prédeterminado e comum às aulas. O tempo necessário para apresentação dos objetivos da pesquisa, distribuição dos questionários, do termo de consentimento livre e esclarecido, preenchimento e recolhimento destes foi de cerca de 40 minutos.

\section{Análise dos dados}

Estatísticas descritivas simples foram conduzidas para levantar os resultados dos questionários aplicados. Quando pertinente, comparações quanto ao sexo do participante foram calculadas (testes $\mathrm{t}$ e de qui-quadrado), na expectativa de diferenças de gênero nas variáveis estudadas, como mencionado pela literatura.

Para a análise da última questão do Questionário Complementar de Amizade, foi feita uma leitura livre para familiarização das respostas e concomitante digitação das mesmas. Em seguida, foi feita uma identificação, por dois avaliadores independentes, de unidades temáticas nas respostas à última questão do instrumento, que possuíam semelhança em conteúdo com os Questionários McGill de Amizade (SOUZA; HUTZ, 2007a) e com o Questionário Complementar de Amizade. Estas unidades temáticas foram agrupadas em categorias mediante análise de conteúdo, seguindo critérios sugeridos por Bardin (1977). As unidades temáticas cujos conteúdos se aproximaram àqueles abordados nas escalas dos questionários McGill 
foram organizadas em categorias de mesmo nome das escalas. Foram elaboradas categorias cujo conteúdo não se assemelha aos Questionários McGill e Complementar, abordando aspectos não mencionados anteriormente pelos instrumentos. Houve consulta a um terceiro avaliador em casos de discordância no processo de julgamento e busca de consenso na construção das categorias. Finalmente, foi efetuado o cálculo das freqüências de respostas em todas as categorias elaboradas.

\section{Resultados}

Primeiramente serão expostos os dados relativos às amizades próximas. Logo após são apresentados os dados sobre a melhor amizade, seguidos dos resultados referentes às amizades extras e às respostas relativas às perguntas qualitativas.

A Tabela 1 apresenta as médias e desvios-padrão para o total de amizades próximas, para amigos próximos do sexo masculino, do sexo feminino, incidência de amizades que moram na mesma cidade, a média da freqüência de contato semanal com estas amizades (muito freqüentemente, freqüentemente, de vez em quando e raramente). Os participantes indicaram um número de amizades próximas que variou de 2 a 10. Não consta na Tabela 1 a média para "encontra raramente" $(0,87)$.

Tabela 1: Média do total de amizades próximas e por sexo, das amizades na mesma cidade e da freqüência de contato semanal

\begin{tabular}{c|c}
\hline Amizades próximas & M (DP) \\
\hline Total & $7,37(2,51)$ \\
Amigos homens & $3,25(1,62)$ \\
Amigas mulheres & $4,12(2,45)$ \\
\hline Reside na mesma cidade & $4,86(2,95)$ \\
\hline Freqüência de contato & \\
Muito freqüentemente & $2,12(2,3)$ \\
Freqüentemente & $2,25(1,75)$ \\
De vez em quando & $2,16(2,01)$ \\
\hline
\end{tabular}

Como se pode ver na Tabela 1, a média de amigos homens indicados foi levemente menor que a média de amigas mulheres indicadas. Por outro lado, os dados sobre amizades próximas por sexo dos participantes foram os seguintes: as mulheres indicaram uma média de 8,7 amigos próximos ( $D P=2,2$ ), apresentando uma média de 2,71 amizades do sexo masculino ( $D P=1,3$ ) e uma média de 5,35 amizades do sexo feminino ( $D P=1,9$ ); já os homens indicaram uma 
média de 6,4 amigos próximos ( $D P=2,7$ ), apresentando uma média de 4,0 amizades do sexo masculino ( $D P=1,7$ ) e uma média de 2,4 amizades do sexo feminino ( $D P=1,9$ ).

Diferenças significativas foram encontradas para amizades próximas de mesmo sexo, ou seja, tanto os participantes homens como as mulheres possuem mais amizades próximas de mesmo sexo: $\mathrm{t}(24)=$ $-2,04(p=0,0053)$; e t $(24)=3,57(p=0,002)$, respectivamente (os cálculos com testes não-paramétricos confirmaram este resultado). Não foram encontradas diferenças significativas em relação ao tempo de duração da melhor amizade, na medida em que as mulheres apresentaram uma média de 6,92 anos ( $D P=5,04)$ e os homens apresentaram uma média de 6,10 anos ( $D P=4,43$ ).

Foi solicitado aos participantes que indicassem se possuíam uma melhor amizade. Caso a resposta fosse negativa, o mesmo deveria responder às perguntas referentes à melhor amizade de acordo com a pessoa que escolheria se tivesse que indicar alguém como melhor amigo. Setenta e nove por cento dos participantes responderam que possuíam uma melhor amizade, enquanto $21 \%$ responderam que não possuíam. Quanto ao tempo de duração da melhor amizade em anos, foi encontrada uma média de 6,58 anos ( $D P=4,71$ ) para o total da amostra. A Tabela 2 apresenta as porcentagens relativas aos dados encontrados sobre melhor amizade: sexo do melhor amigo, origem da amizade, tipo de relacionamento atual e conhecimento do status da amizade.

Tabela 2: Porcentagem do sexo da melhor amizade, origem, relacionamento atual e conhecimento do status de melhor amizade

\begin{tabular}{l|l|c}
\hline \multicolumn{2}{l|}{ Melhor Amizade } & $\%$ \\
\hline Sexo & Feminino & 50 \\
& Masculino & 50 \\
\hline Origem & Escola & 71 \\
& Vizinhança & 8 \\
& Família & 4 \\
\hline Tipo de & Ex-colega de colégio & 46 \\
Relacionamento & Apenas amizade & 25 \\
Atual & Parceiro romântico & 17 \\
& Familiar ou parente & 4 \\
\hline Conhecimento & Colega de faculdade & 4 \\
\hline do status & O amigo sabe & 71 \\
& Não sabe se sabe & 21 \\
\hline
\end{tabular}


Alguns dados não constam na Tabela 2. A porcentagem de melhores amizades que residem na mesma cidade que o participante alcançou $67 \%$. Outros tipos de relacionamento atual com este melhor amigo foram citados, numa porcentagem de 4 . Outras origens da melhor amizade também foram observadas, resultando em $17 \%$.

Em relação ao conhecimento de status, ou seja, se o melhor amigo sabe que é considerado como tal, não houve diferença significativa entre homens e mulheres, segundo o cálculo do qui-quadrado. Isto ocorreu porque dez participantes do sexo feminino e sete do sexo masculino afirmaram que a melhor amizade sabe do status. Já os resultados referentes à média de contatos semanais com o melhor amigo foram: 2,5 ( $D P=2,28$ ) para contato face-a-face; 2,79 ( $D P=$ 2,41 ) para contato por telefone; 1,31 ( $D P=1,98$ ) para contato por e-mail.

Ao responder o questionário, os participantes deveriam, ainda, indicar se possuíam outras pessoas que consideravam como melhor amigo, além daquela indicada anteriormente. A quantidade de amizades extras indicadas variou de 1 a 6 , sendo que $25 \%$ dos participantes indicou mais uma melhor amizade extra e $21 \%$ indicou mais três. A média total de amizades extras indicadas foi de $2,50(D P=1,76)$, enquanto a média de amizades extras do sexo feminino indicada foi de 1,62 ( $D P=1,49)$ e a do sexo masculino foi de 0,87 .

No início do questionário, havia uma pergunta aberta na qual os indivíduos que compuseram a amostra deveriam responder se possuíam um hobby ou lazer preferido e, caso a resposta fosse afirmativa, deveriam indicar qual era. Os resultados, categorizados de acordo com o tipo de atividade indicada e a freqüência com que cada um apareceu, foram os seguintes: as categorias esportes (exemplo: futebol), leitura e praticar artes (exemplo: canto) tiveram uma freqüência de seis respostas; as categorias ouvir música e sair (por exemplo, com os amigos), apresentaram uma freqüência de cinco indicações; as categorias conversar (por exemplo, ao telefone), jogar (exemplo: RPG), namorar e televisão foram citadas com uma freqüência de duas vezes; por fim, a categoria dormir foi apontada apenas uma vez.

Como já referido, havia também, no final do questionário, uma pergunta qualitativa na qual o participante deveria escrever se existia algum aspecto importante da amizade que não havia sido mencionado anteriormente. As respostas a esta pergunta foram categorizadas e tiveram suas frequências calculadas. A categoria mais citada foi aliança confiável, com uma freqüência de quatro respostas, seguida da categoria intimidade, que foi apontada três vezes. As categorias distância relacional, respeito e aceitação, tiveram uma frequência de duas respostas, enquanto as categorias possibilidade de melhor amizade exclusiva, dedicação, laços fortes e origem e manutenção da amizade tiveram a freqüência de apenas 
uma indicação cada.

\section{Discussão}

Em um primeiro momento são debatidos os resultados sobre as amizades próximas. Posteriormente são discutidos os achados para as melhores amizades, seguidos da discussão dos dados encontrados sobre as melhores amizades extras. Por fim, serão comentados os dados qualitativos relacionados aos aspectos importantes da amizade e às categorias de hobby/lazer que foram apresentados pelos participantes.

Como encontrado por Souza e Hutz (2008), em uma pesquisa feita com adultos, os resultados mostraram uma predominância significativa de indicações de amizades próximas de mesmo sexo. Um resultado interessante do presente trabalho e que contraria a literatura prévia - no caso, o estudo de Silva et al. (2004) - foi um maior número de amizades próximas nas meninas (média de 8,7 ) do que nos meninos (média de 6,4). Um terceiro estudo será necessário para se poder concluir sobre a tendência para quantidade de amizades próximas em adolescentes brasileiros.

Os dados sobre a média de amizades próximas segundo a freqüência de contato semanal (muito freqüentemente, freqüentemente, de vez em quando e raramente) permitem a inferência de que um contato freqüente tem grande importância em uma amizade para os adolescentes "calouros". A média de amizades próximas com que os participantes têm raro encontro face-a-face foi pequena em relação às demais modalidades de contato.

O presente estudo também não apresentou diferença estatisticamente significativa nas médias de tempo de melhor amizade para homens e para mulheres, da mesma forma como ocorreu no estudo de Souza e Hutz (2008). No entanto, ao contrário do último, o presente trabalho encontrou uma média levemente maior dentre as meninas.

Ainda em relação ao estudo citado com adultos-jovens, o tempo médio de duração da amizade dos adolescentes "calouros", em anos ( mulheres $=6,92$; e homens $=6,10$ ), foi menor que o tempo médio de melhor amizade encontrado no trabalho com adultos (mulheres $=$ 8,5; e homens $=9,1$ ). Não tendo sido encontrada literatura que explique a diferença entre tempo de melhor amizade na adolescência (dados do presente estudo) e na juventude e adultez jovem (dados do estudo de Souza e Hutz), é possível, no entanto, construir uma hipótese-explicativa. O fato de que a amostra do presente estudo é constituída por participantes com menos tempo de vida pode explicar tal diferença.

Mesmo sendo a busca por novas amizades e afetos uma característica específica da entrada na universidade (PAGOTTI; PAGOTTI, 2005), os resultados obtidos mostraram uma manutenção dos vínculos que 
foram estabelecidos antes dessa entrada. Como visto, $46 \%$ dos participantes apontaram, como melhor amigo, um ex-colega de colégio e apenas um participante apontou um colega de faculdade (porém, o havia conhecido no colégio). Estes dados podem ter sido encontrados devido ao fato de que todos os participantes cursavam o primeiro período (semestre) do curso de graduação. Assim, tiveram poucos meses de contato com os colegas de faculdade. De qualquer forma, os resultados aqui descritos demonstram que, mesmo após o ingresso na universidade, há uma manutenção de vínculos estabelecidos antes do início do curso. Já quanto à freqüência de contato semanal com o melhor amigo, observou-se que apesar de atualmente 0 acesso à Internet ser facilitado, o contato por e-mail não é de grande relevância nas melhores amizades em adolescentes calouros.

No entanto, aproximando estes dados para frequência de contato com os encontrados por Pylro (2007), é possível afirmar que a presente amostra de adolescentes também valoriza mais os contatos face-a-face ou por telefone, deixando a Internet como um meio secundário às amizades mais íntimas. A este respeito, Sant'Anna (2007), ao examinar o papel mediador do telefone celular nas amizades de adolescentes, percebeu que o celular eleva o nível de proximidade entre os amigos, além de favorecer o planejamento de atividades compartilhadas. De fato, no presente trabalho a maior média do tipo de contato com a melhor amizade foi com o uso do telefone, corroborando os resultados recentes do estudo de 2007.

Curiosamente, apesar de $71 \%$ dos participantes afirmarem que a amizade teve origem no colégio, apenas $46 \%$ da amostra afirmou que o relacionamento atual com o melhor amigo é de ex-colega de colégio. É possível inferir, portanto, que parte das melhores amizades que surgiram no colégio têm outro tipo de relacionamento atual com o participante, o que sugere a manutenção de atividades comuns entre amigos.

Confirmando os achados de Minto et al. (2006), referidos na introdução, os jovens pouco a pouco se afastam da família, levando a um estreitamento de laços com os pares. Como se pôde constatar, somente um participante indicou um familiar como melhor amigo. A maioria dos participantes (71\%) afirmou que o melhor amigo sabe de seu status na "pirâmide das amizades", assim como encontrado na pesquisa realizada com adultos (SOUZA; HUTZ, 2008), na qual a porcentagem foi de $66,7 \%$.

Em relação às melhores amizades extras, os dados encontrados no presente estudo foram semelhantes aos encontrados por Souza e Hutz (2008). Assim, naquela amostra de jovens adultos encontrou-se $27 \%$ de indivíduos que indicaram mais uma melhor amizade extra, enquanto na amostra de adolescentes calouros a porcentagem foi de $25 \%$. Já a porcentagem de indicações de três melhores amizades 
extras em Souza e Hutz (2008) foi de $17 \%$, enquanto no presente trabalho foi de $21 \%$.

Considerando-se que as categorias de hobby/lazer referentes a esportes, sair, conversar, jogar e namorar são atividades que normalmente envolvem mais de uma pessoa, pode-se afirmar que são atividades sociais. Como foi encontrado que tais atividades apareceram com uma freqüência total de $46 \%$ na presente amostra, é possível inferir que atividades realizadas com outras pessoas, inclusive amigos, são de grande importância para estes "calouros" adolescentes.

Em relação às respostas qualitativas sobre aspectos importantes da amizade que não foram mencionados no questionário, observou-se que, assim como encontrado por Duarte e Souza (no prelo) em amostra com universitários adultos, a categoria mais mencionada foi aliança confiável, seguida de intimidade. Nas categorias referentes ao Questionário Complementar de Amizade, o tema mais mencionado foi distância relacional. Isso demonstra a importância destas características em uma amizade, tanto para adultos, como para adolescentes universitários.

A partir de todos os resultados encontrados, é possível concluir que, conforme aponta a literatura sobre o tema, a amizade em adolescentes que acabaram de ingressar na universidade é de grande relevância, sendo ela principalmente estabelecida antes de tal ingresso. São necessários novos estudos que investiguem se essa característica e origem se mantêm em épocas posteriores, ou seja, períodos medianos e finais da graduação.

\section{Considerações finais}

Ao analisar os resultados encontrados, é importante salientar o fato de que a amostra é pequena, o que gera limitações na interpretação e generalização dos mesmos. Sendo assim, são necessários novos estudos que tratem sobre o tema da amizade em "calouros" adolescentes. Além disso, uma sugestão de pesquisa é comparar a percepção e qualidade dos relacionamentos de amizade em calouros adolescentes com estudantes que estejam cursando períodos intermediários e finais da graduação.

Apesar das limitações relacionadas ao tamanho da amostra, o presente estudo contribui para uma melhor compreensão desta fase peculiar da vida de alguns adolescentes - o ingresso na universidade. Além disso, abre possibilidades para futuras investigações que promovam um melhor entendimento sobre este tema de estudo.

\section{Referências Bibliográficas}

ARAÚJ O, L. B.; GOMES, W. B. Adolescência e as expectativas em relação aos efeitos do álcool. Psicologia: reflexão e crítica, Porto 
Alegre, v. 11, n. 1, p. 5-33, 1998.

ARIĖS, P. História social da criança e da família (D. Flaksman, Trad.). Rio de Janeiro: Editora Guanabara Koogan, 1981. (Originalmente publicado em 1973)

BARDIN, L. Análise de conteúdo (L. A. Reto e A. Pinheiro, Trads.). Lisboa: Edições 70, 1977.

BUKOWSKI, W.; NEWCOMB, A.; HARTUP, W. (Orgs.). The company they keep: friendship in childhood and adolescence. Cambridge: University Press, 1996.

CARBERY, J.; BUHRMESTER, D. Friendship and need fulfillment during three phases of young adulthood. Journal of social and personal relationships, Thousand Oaks/Londres, v. 15, n. 3, p. 393-409, 1998.

CORDEIRO, R. A. Aparência física e amizade íntima na adolescência: Estudo num contexto pré-universitário. Análise psicológica, Lisboa, v. 4, n. XXIV, p. 509-517, 2006.

DUARTE, M. G.; SOUZA, L. K. O que importa em uma amizade? A percepção de universitários sobre amizades. Interpersona: an international journal on personal relationships, v. 4, no prelo.

ERIKSON, E. I dentidade, juventude e crise. $2^{a}$ ed. Rio de Janeiro: Zahar Editores, 1976. (Originalmente publicado em 1968)

ESTATUTO DA CRIANÇA E DO ADOLESCENTE. Diário Oficial da União. Lei $\mathbf{n}^{\circ}$ 8069, de 13 de julho de 1990. Brasília: Palácio do Planalto, 1990.

GÜNTHER, I. A. Preocupações de adolescentes ou os jovens têm na cabeça mais do que bonés. Psicologia: teoria e pesquisa, Brasília, v. 12, p. 61-69, 1996.

HARTUP, W. Behavioral manifestations of children's friendships. In: BERNDT, T.; LADD, G. (Orgs.). Peer relationships in child development. New York: Wiley \& Sons, 1989. p. 46-70.

IGUE, E.; BARIANI, I.; MILANESI, P. Vivência acadêmica e expectativas de universitários ingressantes e concluintes. Psico-USF, Itatiba, v. 13, n. 2, p. 155-164, 2008.

LEMA, C. C. de. Amizade: relações de apoio e intimidade na adolescência. 1997. 212f. Dissertação (Mestrado em Psicologia) Faculdade de Psicologia, Pontifícia Universidade Católica do Rio Grande do Sul, Porto Alegre.

LISBOA, C.; KOLLER, S. H. Amizade e vitimização: Fatores de risco e proteção no contexto do grupo de iguais. Psico (PUC-RS), Porto Alegre, v. 34, n. 1, p. 57-70, 2003.

MARQUES, J. C. Relações interpessoais e processos de grupo: 0 conceito de intimidade. Psico (PUC-RS), Porto Alegre, v. 24, n. 2, p. 9-22, 1993.

MARTINS, P.; TRINDADE, Z.; ALMEIDA, A. O ter e o ser: Representações sociais da adolescência entre adolescentes de inserção urbana e rural. Psicologia: reflexão e crítica, Porto Alegre, 
v. 16, n. 3, p. 555-568, 2003.

MINTO, E.; PEDRO, C.; NETTO, J.; BUGLIANI, M.; GORAYEB, R. Ensino de habilidades de vida na escola: Uma experiência com adolescentes. Psicologia em estudo, Maringá, v. 11, p. 561-568, 2006.

MONSOUR, M. Meanings of intimacy in cross- and same-sex friendships. Journal of social and personal relationships, Thousand Oaks/Londres, v. 9, p. 277-295, 1992.

MOREIRA, A. O ensino superior. Disponível em: $<$ http://www.psicologia.com.pt/>. Acesso em: 10 mai. 2008.

OLIVEIRA, C.; COSTA, A. Os dilemas morais e não-morais no cotidiano de conflitos de adolescentes de Minas Gerais. Psicologia: reflexão e crítica, Porto Alegre, v. 8, n. 1, p. 73-90, 1995.

OZELLA, S. Adolescência: Uma perspectiva crítica. In: CONTINI, M.; KOLLER, S. H.; BARROS, M. (Orgs.). Adolescência e psicologia: concepções, práticas e reflexões críticas. Brasília: CRP, 2002. p. 1624.

PAGOTTI, G.; PAGOTTI, A. As preocupações dos estudantes universitários: Um estudo exploratório. Revista psicopedagogia, São Paulo, v. 22, n. 68, p. 94-104, 2005.

PEREIRA, F.; GARCIA, A. Amizade e escolha profissional: Influência ou cooperação? Revista brasileira de orientação profissional, Ribeirão Preto, v. 8, n. 1, p. 71-86, 2007.

PORTES, E. Trajetórias escolares e vida acadêmica do estudante pobre da UFMG: um estudo a partir de cinco casos. 2001. 264f. Tese (Doutorado em Educação) - Faculdade de Educação, Universidade Federal de Minas Gerais, Belo Horizonte.

POULIN, F.; PEDERSEN, S. Developmental changes in gender composition of friendship networks in adolescent girls and boys. Developmental psychology, v. 43, n. 6, p. 1484-1496, 2007.

PYLRO, R. Amiz@de.com: Amizade e adolescência na era da Internet. 2007. 137f. Dissertação (Mestrado em Psicologia) - Centro de Ciências Humanas e Naturais, Universidade Federal do Espírito Santo, Vitória.

RAWLINS, W. Friendship matters. New York: Aldine de Gruyter, 1992.

RAYOU, P. Crianças e jovens, atores sociais na escola: Como os compreender? Educação e sociedade, Campinas, v. 26, n. 91, p. 465-484, 2005.

SANT'ANNA, H. Díades mediadas: A telefonia celular na amizade entre adolescentes. 2007. 121f. Dissertação (Mestrado em Psicologia) - Centro de Ciências Humanas e Naturais, Universidade Federal do Espírito Santo, Vitória.

SHARABANY, R. Intimate Friendship Scale: Conceptual underpinnings, psychometric properties and construct validity. Journal of Social and personal relationships, Thousand Oaks/Londres, v. 11, p. 
449-469, 1994.

SILVA, A.; SOARES, D. A orientação profissional como rito preliminar de passagem: Sua importância clínica. Psicologia em estudo, Maringá, v. 6, n. 2, p. 115-121, 2001.

SILVA, M.; SCHOEN-FERREIRA, T.; MEDEIROS, E.; AZNAR-FARIAS, M.; PEDROMÔNICO, $M$. O adolescente e a competência social: Focando o número de amigos. Revista brasileira de crescimento e desenvolvimento humano, São Paulo, v. 14, n. 1, p. 23-31, 2004. SOUZA, L. K.; HUTZ, C. S. A qualidade da amizade: Adaptação e validação dos Questionários McGill. Aletheia, Canoas, v. 25, p. 8296, 2007a.

- Diferenças de gênero na percepção da qualidade da amizade. Psico (PUC-RS), Porto Alegre, v. 38, p. 125-132, 2007b.

Amizade na Adultez: Fatores Individuais, Ambientais, Situacionais e Diádicos. I nteração em psicologia, Curitiba, v. 12, n. 1, p. 77-85, 2008.

SULLIVAN, H. S. The interpersonal theory of psychiatry. New York: Norton, 1953.

\section{Endereço para correspondência}

Suellen Ibrahim Peron

UFMG, FAFICH, Depto. de Psicologia, Av. Antônio Carlos, 6627, sala F-4050, Campus Pampulha, CEP 31.270-901, Belo Horizonte-MG, Brasil.

Endereço eletrônico: suellenperon@hotmail.com

Luisa Schivek Guimarães

UFMG, FAFICH, Depto. de Psicologia, Av. Antônio Carlos, 6627, sala F-4050, Campus Pampulha, CEP 31.270-901, Belo Horizonte-MG, Brasil.

Endereço eletrônico: luschivek@yahoo.com.br

Luciana Karine de Souza

UFMG, FAFICH, Depto. de Psicologia, Av. Antônio Carlos, 6627, sala F-4050, Campus Pampulha, CEP 31.270-901, Belo Horizonte-MG, Brasil.

Endereço eletrônico: lucianak@fafich.ufmg.br

Recebido em: 23/06/2008

Aceito para publicação em: 10/03/2010

Acompanhamento do processo editorial: Eleonôra Torres Prestrelo

\section{Notas}

* Doutora em Psicologia pela Universidade Federal do Rio Grande so Sul - UFRGS.

${ }^{1} O$ presente texto é resultado da análise de dados inéditos, coletados para os estudos de doutorado da terceira autora, que agradece o trabalho em iniciação científica voluntária das duas primeiras autoras sobre os dados referidos, podendo torná-los públicos. Agradecimentos a M. G. Duarte, à equipe do Grupo de Pesquisa (CNPq) “Desenvolvimento Humano: Processos Cognitivos e Interacionais" e a C. S. Hutz. Agradecemos também aos pareceristas desta publicação, cujos apontamentos colaboraram para a melhoria do trabalho. 